\title{
Masculinidades no Cárcere: Homens que Visitam suas Parceiras Privadas de Liberdade
}

\author{
Helena Salgueiro Lermen ${ }^{1}$ \\ Martinho Braga Batista e Silva ${ }^{1}$ \\ ${ }^{1}$ Universidade do Estado do Rio de Janeiro, RJ, Brasil. \\ ${ }^{1}$ Universidade do Estado do Rio de Janeiro, RJ, Brasil.
}

Resumo: $\mathrm{O}$ abandono de mulheres no cárcere tem sido documentado por pesquisadores do Brasil. A ausência mais apontada é dos homens que têm parceiras encarceradas. Não por acaso, nenhuma pesquisa específica sobre esses sujeitos foi encontrada na literatura nacional e internacional. Visando suprir, em parte, essa lacuna bibliográfica, foram investigados os cônjuges que frequentam duas penitenciarias femininas em dias de visitas. Através das lentes de gênero, buscou-se compreender os significados atribuídos por eles para manutenção dos relacionamentos com as companheiras presas. Para isso, realizou-se uma etnografia nas filas de espera das prisões. Na coleta, foram identificados 26 homens companheiros que regularmente frequentam o cárcere feminino em dias de visitas, dos quais quatro foram entrevistados. Embora o número encontrado ainda seja tímido, permite problematizar a categoria "abandono" na cadeia de mulheres. Acerca das trajetórias dos entrevistados, observa-se o exercício simultâneo das masculinidades hegemônica e não hegemônica. Todos são homens provedores, financeiramente estáveis e consideravelmente mais velhos que suas parceiras. Paralelamente, os quatro eram, de algum modo, cuidadores antes do encarceramento de suas companheiras. Para eles, a visita na prisão feminina representa amor, dever e cuidado. Ao mesmo tempo, entende-se que essas relações representam a possibilidade de exercício de controle e poder masculino sobre essas mulheres presas, visto que todas elas têm vidas marcadas por fragilidades familiares e sociais.

Palavras-chave: Prisões, Gênero, Masculinidade, Conjugalidade.

\section{Masculinities Inside Prison: Men who Visit their Female Partners Deprived of Liberty}

\begin{abstract}
The abandonment of women in prison has been documented by Brazilian researchers. The most highlighted absence is that of men whose female partners are incarcerated. Not by chance, no specific research on these subjects was found in national or international scientific literature. Aiming to remedy, to some extent, this bibliographical gap, we investigated male partners who attend two penitentiaries in visiting days. Through gender lenses, we aimed to understand the meanings attributed by them in order to maintain their relationships with the imprisoned partners. To achieve that, we conducted an ethnography in the prison-visiting queues. In data collection, 26 male partners who regularly attend female correctional facilities were identified, four of which have been interviewed. Although these numbers are still low, they allow the problematization of the category "abandonment" within female prisons. Concerning the interviewees' trajectories, we perceived the simultaneous exercise of hegemonic and non-hegemonic masculinities. All of them are providers, financially stable and substantially older than their partners. In addition to that, the four of them were, in some way, caretakers before their partners' imprisonment. For them, visiting the female prison represents love, duty and care. At the same time, we understand that these relationships represent the possibility of exercising control and male power over these imprisoned women, since they all have lives marked by family and social frailties.
\end{abstract}

Keywords: Prisons, Gender, Masculinity, Conjugality. 


\title{
Masculinidades en la Cárcel: Hombres que Visitan a sus Compañeras Privadas de Libertad
}

\begin{abstract}
Resumen: El abandono de mujeres en la cárcel ha sido documentado por investigadores en Brasil. La ausencia más notoria es la de los hombres cuyas compañeras están encarceladas. No por casualidad, ninguna investigación específica acerca de estos sujetos ha sido encontrada en la literatura nacional e internacional., Con el fin de suplir, en parte, esa laguna bibliográfica fueron investigados los conyugues que frecuentan dos penitenciarias femeninas en días de visitas. A través de las lentes de género, se buscó comprender los significados por ellos atribuidos a la manutención de la relación con sus compañeras presas. Para tal, se realizó una etnografía en las filas de espera de las prisiones. En la colecta, fueron identificados 26 hombres compañeros que frecuentan regularmente la cárcel femenina en días de visitas, entre ellos, cuatro fueron entrevistados. Aunque el número encontrado todavía sea tímido, permite problematizar la categoría "abandono" en la cárcel de mujeres. Acerca de las trayectorias de los entrevistados, se observa el ejercicio simultáneo de las masculinidades hegemónica y no hegemónica. Todos los hombres son proveedores, financieramente estables y considerablemente más viejos que sus compañeras. En paralelo, los cuatro eran, de alguna manera, cuidadores, antes del encarcelamiento de sus compañeras. Para ellos, la visita en la cárcel femenina representa amor, deber y cuidado. Al mismo tiempo, se entiende que estas relaciones representan la posibilidad del ejercicio de control y poder masculino sobre estas mujeres presas, dado que todas ellas tienen vidas marcadas por fragilidades familiares y sociales.
\end{abstract}

Palabras clave: Prisiones, Género, Masculinidad, Conyugalidad.

\section{Introdução}

Entre os anos de 2000 a 2016, houve um aumento de $656 \%$ da população prisional feminina no Brasil, totalizando, na atualidade, mais de 42 mil mulheres detidas (Brasil, 2018). Junto com a expansão da população prisional, crescem os grupos que frequentam as prisões, como os visitantes. Esses sujeitos são fundamentais no cotidiano prisional, porque as pessoas presas carecem de redes de apoio estatais que favoreçam a reinserção social, contando quase que exclusivamente com o suporte de suas famílias neste processo. Assim, os papéis desempenhados pelos visitantes, tais como a provisão material e a busca por serviços jurídico, de saúde e de assistência social são fundamentais para os seus entes presos (Bassani, 2016; Minayo, \& Ribeiro, 2016; Pereira, 2016).

Via de regra, as mulheres são visitantes do cárcere. Em prisões masculinas, é notória a presença das visitadoras, em especial das mães e companheiras dos sujeitos detidos (Barcinski, Lermen, Campani, \& Altenbernd, 2014; Bassani, 2011; 2016; Biondi,
2009; Guimarães et al., 2006; Pereira, 2016). Nos estabelecimentos penais femininos, o grupo é mais modesto e composto, em sua maioria, por mães, filhas (Altenbernd, Barcinski, \& Lermen, 2015; Foltran, 2010; Medeiros, 2010; Pereira, 2016) e amigas (Diniz, 2015) das mulheres encarceradas.

De modo geral, a população prisional masculina é mais visitada que a feminina. Em média, são 7,8 visitas por homem preso e 5,9 por mulher encarcerada. Esses números variam muito entre os Estados, visto que há unidades federativas nas quais a média de visitas em prisões femininas é cinco vezes menor que nas masculinas (Brasil, 2018). A distância entre a residência dos parentes e a prisão, a sobrecarga com os cuidados da prole da mulher detida, o estigma de ter uma familiar que cometeu uma transgressão da lei encarcerada (Minayo, \& Ribeiro, 2016; Simões, 2014) são algumas das razões pelas quais a população prisional feminina recebe menos visitas se comparadas aos homens encarcerados. A ausência da família é, por vezes, solicitada pelas próprias mulheres privadas de liberdade, que não desejam que sua família passe 
constrangimentos e humilhações perante a revista íntima (Pimentel, 2018).

Um fenômeno que tem sido documentado por pesquisadores, em sua maioria da área da Psicologia, é o número pequeno ou inexistente de homens companheiros que frequentam o cárcere feminino em dias de visitas (Barcinski, 2012; Bassani, 2016; Carvalho, Valente, Assis, \& Vasconcelos, 2006; Diniz, 2015; Diuana, Ventura, Simas, Larouzé, \& Correa, 2016; Guimarães et al., 2006; Foltran, 2010; Medeiros, 2010; Minayo, \& Ribeiro, 2016; Modesti, 2013; Pereira, 2016; Simões, 2014; Soares, Félix-Silva, \& Figueiró, 2014). De modo geral, essas pesquisas reforçam a ideia do abandono feminino, ou seja, da ausência dos companheiros quando do encarceramento das mulheres. Alguns estudos mencionam a existência de homens que visitam suas parceiras na prisão (Diniz, 2015; Pereira, 2016), inclusive em países como Israel (Einat, \& Rabinovitz, 2013), porém nenhuma pesquisa específica sobre esses sujeitos foi encontrada na literatura nacional e internacional.

Considerando a enorme importância que os visitantes têm nas prisões e buscando suprir, em parte, essa lacuna bibliográfica, realizou-se um estudo com homens que visitam suas parceiras em prisões femininas de regime fechado. A pouca frequência de visitantes no cárcere feminino explicita a importância de entendermos que a prática criminosa e as condutas de encarceramento são permeadas de significados que só podem ser analisados através das prescrições sociais que impactam diferentemente mulheres e homens na sociedade. Assim, o presente estudo parte de uma perspectiva de gênero, conceito que se fundamenta em questões sociais e no modo como essas são atravessadas pelas relações de poder (Scott, 1990). Através das lentes de gênero, esta pesquisa se propõe compreender os significados atribuídos pelos homens para manutenção dos relacionamentos com as companheiras presas. Conhecer tais significados pode dar pistas dos motivos pelos quais a maior parte das mulheres em situação de prisão no Brasil não recebe visitas de seus cônjuges.

\section{Masculidades no cárcere: questões de gênero}

Santos e Nardi (2014) percorrem as políticas de saúde voltadas para os homens e para os privados de liberdade, para relevar o diagrama de forças em jogo na produção de masculinidades criminalizadas.
A violência, notória no cotidiano carcerário, também é apontada como elemento da sociabilidade masculina, bem como a maior disponibilidade em assumir riscos, contrastando com a expectativa das políticas mencionadas: gerar sujeitos que se cuidem e ao mesmo tempo procurem cuidados quando percebem que necessitam dele. Nas palavras dos autores, "num espaço essencialmente masculino, cuidar da saúde é o último predicado atribuído às masculinidades viris" (p. 944). As masculinidades criminalizadas são consideradas viris e heteronormativas pelos autores, já que tais padrões de comportamento impostos repelem a manifestação de fragilidades e coíbem qualquer demanda de cuidado.

Esse debate sobre masculinidades no cárcere remonta aos anos 1990 pelo menos, quando Silva (1997) apresenta um estudo de caso sobre violência sexual em um presídio masculino, também concluindo que a "masculinidade hegemônica exigida na cadeia é a heterossexual" (p. 137). Um rapaz acusado de estuprar a namorada é aprisionado pela primeira e única vez - configurando-se como um "novato" frente aos demais - e dentro da cela coagido a praticar sexo com alguns dos homens reclusos, as justificativas para tais práticas sexuais remetendo a um código de honra peculiar, no interior do qual cabe "uma identidade masculina (sentirem-se homens), com uma vida sexual homossexual e desejo por pessoas do sexo oposto (como é comum acontecer na cadeia em razão do confinamento)" (p. 130). A interpretação que se segue à narrativa tem como base as contribuições de Peter Fry sobre práticas e identidades sexuais no Brasil, sublinhando a manutenção da identidade heterossexual quando de práticas homossexuais entre homens, o papel ativo na relação permitindo tal manutenção e o passivo ameaçando-a. Lopes (2005) também aborda o estupro em presídios masculinos, cunhando o conceito "masculinidades encarceradas" ao entrevistar não só os privados de liberdade como também os agentes penitenciários.

Mesmo quando nos deslocamos da privação para a restrição da liberdade, das unidades prisionais para os que cometem crimes em direção às socioeducativas para os que cometem infrações, encontramos referências a essas masculinidades viris, agora nomeadas "hegemônicas" e indicadas como frequentes entre jovens (Nascimento, Uziel, \& Hernandez, 2018). Segundo os autores dessa pesquisa-ação com mais de uma centena de interlocutores em 
algumas unidades, o machismo e as noções rígidas de gênero e sexualidade são fatores importantes nas concepções desses jovens sobre saúde, especialmente sexual e reprodutiva, sendo que os internos proferem discursos que naturalizam a violência e a paternidade como signos importantes da demonstração pública da masculinidade.

Entrevistando inclusive os profissionais responsáveis pela socioeducação, os autores notam resistências à oferta de visita íntima, bem como à distribuição de preservativos, ao mesmo tempo em que relevam que os jovens evitam a masturbação após dias de visita com base em códigos de honra peculiares. Normas de gênero influenciam o manejo da sexualidade nestas instituições, com efeitos sobre a saúde que se deixam ver nesta cartografia que aborda não só as masculinidades hegemônicas, como também as dissidentes: os jovens em cumprimento de medida socioeducativa que se declaram homossexuais são separados dos demais em celas específicas (Nascimento et al., 2018, p. 5).

Salienta-se que o conceito de masculinidade hegemônica surge como alternativa ao de patriarcado, este último considerado uma estrutura muito abstrata (Nascimento, \& Connell, 2017), na qual os atores envolvidos e os mecanismos em ação são ocultados. Um dos estudos sobre encarceramento em massa no qual o patriarcado é um recurso explicativo fundamental para a seletividade penal foi desenvolvido por Borges (2018), mostrando a relevância de análises sobre este fenômeno com recorte de gênero, classe e principalmente raça.

Ao longo da década de 1980 o conceito de masculinidade hegemônica foi apresentado como uma contribuição da teoria social aos estudos de gênero (Carrigan, Connell, \& Lee, 1985), visibilizando as possibilidades de contestação e as maneiras pela qual as hierarquias operam através de entrevistas com jovens no setor educação. Essas vias de contestação à dita masculinidade hegemônica apontam justamente para modalidades variadas de exercício da paternidade, nas quais o cuidado é marcante (Nascimento, \& Connell, 2017).

Levando em conta tal perspectiva sobre masculinidade, apresentamos as duas questões a seguir: as masculinidades no cárcere podem ser consideradas exclusivamente heteronormativas, pouco permeáveis à exposição de fragilidades e à demanda de cuidado nas unidades prisionais femininas? Haveria espaço para a emergência de masculinidades não hegemônicas entre visitantes dessas unidades?

\section{Método}

O presente estudo surgiu como continuação da pesquisa de mestrado em Psicologia Social realizado pela primeira autora, sobre mulheres que conceberam filhos no cárcere masculino em dias de visita. O interesse pela temática emergiu através da experiência profissional da pesquisadora como psicóloga em uma prisão exclusivamente masculina. No local, era nítida a grande quantidade de mulheres que visitavam o cárcere e que realizavam o registro de paternidade dos filhos. Ao estudar a temática da visitação no cárcere, a pesquisadora deparou-se com os contrastes entre as longas filas de mulheres em dias de visita à cadeia masculina com os achados na literatura acerca das ausências, sobretudo de homens visitantes, em prisões femininas.

Visando encontrar os homens que visitam as parceiras encarceradas, a pesquisadora frequentou o lado de fora de duas penitenciárias femininas de regime fechado da Região Sul do país. Como a etnografia conduzida por Biondi (2009) em um centro de detenção, participou da fila de espera em dias de visita e não gravou os dados coletados, registrando-os posteriormente em diário de campo; diferentemente da referida autora, realizou observação participante do cotidiano das duas instituições prisionais femininas e não masculinas, em especial das interações entre os visitantes e não entre os privados de liberdade.

Segundo Cunha (2014), cada vez mais etnografias vêm sendo conduzidas em unidades prisionais. A autora destaca a permeabilidade das fronteiras da prisão e os diferentes modos através dos quais ela tem sido estudada etnograficamente. Uma das formas de documentar essas fronteiras "porosas" das unidades prisionais é colocar-se disponível para uma interlocução com os visitantes nas filas de espera nas prisões e assim ocupar-se das "relações entre a prisão-sociedade e da articulação entre os mundos interno e externo" do cárcere (Cunha, 2014, p. 227).

Em cinco meses de coleta, durante os anos de 2017 e 2018, a pesquisadora identificou 26 homens que visitam as parceiras presas, dos quais quatro ela entrevistou. Foram semanas convivendo com esses sujeitos na fila de espera, antes de formalizar a entrevista. Essas ocorreram em uma cafeteria próxima a uma das prisões. No mestrado, os depoi- 
mentos das mulheres visitantes foram coletados na mesma prisão masculina onde a pesquisadora havia trabalhado, anos antes, como psicóloga. Esta coleta de dados ocorreu, propositalmente, nos dias em que eram feitos os registros de nascimento de crianças que têm pais presos no local. Não por acaso, as mulheres com quem a pesquisadora conversou achavam que ela trabalhava como psicóloga na instituição e que a entrevista fazia parte do procedimento de registro dos bebês. Isso, naturalmente, impactou os resultados obtidos.

Desse modo, no presente estudo, o intuito era não ultrapassar a fronteira da prisão feminina. Para isso, era fundamental encontrar um local adequado para as entrevistas, que pudesse garantir o sigilo das informações coletadas e que fosse conveniente para os participantes. A cafeteria preenchia todos esses requisitos. Os participantes não se opuseram à sugestão do local para entrevista e não manifestaram desconforto de narrar algumas de suas histórias nesse espaço. Nas entrevistas foram abordadas as histórias de vida do homem visitante e suas parceiras detidas, bem como as motivações e dificuldades para manutenção da relação amorosa com companheiras encarceradas. Foram investigados ainda o cotidiano dos participantes em dia de visita e as experiências masculinas no cárcere de mulheres.

Para a realização da coleta de dados, aspectos éticos foram garantidos. A presente etnografia passou pela apreciação de um Comitê de Ética em Pesquisa e os participantes assinaram o Termo de Consentimento Livre e Esclarecido. Além disso, não foi identificado o município ou estado da federação no qual o trabalho de campo foi conduzido, apenas a Região do país, justamente para garantir o anonimato dos participantes, dada a pequena quantidade de visitantes em estabelecimentos femininos no Brasil. Os resultados a seguir são centrados nos dados obtidos nas entrevistas, embora alguns fragmentos dos diários de campo também sejam apresentados. As observações, encontros e prosas coletados na fila de espera e no entorno das prisões femininas são intercalados aos relatos do quarteto entrevistado.

\section{Resultados}

Interações e diálogos foram estabelecidos com 126 visitantes, 76 mulheres e 50 homens. Dentre o grupo feminino, as mães são maioria (36), seguidas pelas filhas (12). Já no conjunto masculino, os companheiros representam mais da metade (26) dos visitantes. Quatro deles - Gregório, Teodoro, Sebastião e Ciro - dividiram parte de suas trajetórias com a pesquisadora, em uma conversa regada a café.

\section{Gregório}

Gregório tem 37 anos, possui ensino superior completo e declara-se pardo. Reside em um município da região metropolitana. Trabalha 44 horas semanais em uma empresa e sua renda é de $\mathrm{R} \$ 4.500,00$. Possui união estável com Luzia, 26 anos, que está presa. A formalização da relação foi uma exigência da instituição prisional para que ele pudesse visitar a parceira no cárcere. Gregório mora com as duas filhas. Ivana, de 11 anos, é fruto de um relacionamento anterior. Já Iara, 7 anos, é filha biológica de Luzia. Em abril de 2016, após a prisão da companheira, Gregório registrou a menina como sua. Para os cuidados com as filhas, conta com o apoio de sua mãe, irmão, avó e avô.

Sete anos atrás, o casal se conheceu. À época, eles tinham relações conjugais com outras pessoas. Gregório terminou o casamento e ficou com a guarda de Ivana, sua filha. Já Luzia engravidou do então companheiro e foi rejeitada por ele. Como "não tinha pra onde ir", Gregório ofereceu a ela abrigo e iniciaram o relacionamento amoroso. Separaram-se depois de um tempo e reataram o romance em 2013.

O delito pelo qual Luzia foi presa ocorreu em 2012, durante o período em que estavam afastados. Ela recebeu uma pena de 10 anos por abuso sexual de uma menina de 11 anos. Gregório desresponsabiliza a companheira, não acredita que ela tenha cometido o delito. A condenação de Luzia ocorreu em abril de 2016, desde então está presa.

Gregório é a única pessoa que visita Luzia. Ele não tem experiências anteriores com a prisão, nunca foi preso ou visitou outras pessoas no cárcere. No seu cotidiano como visitante, prepara a comida que leva à cadeia. Como foi ensinado desde criança a cozinhar, não nota significativas diferenças em relação a sua rotina depois que a parceira foi presa. Frequenta o presídio todas as quartas, para entregar a "sacola" $\mathrm{e}$ todos os sábados, dia de visita. Nesses dias, também transporta itens de higiene e

${ }^{1}$ Conjunto de materiais que os visitantes levam às mulheres presos. Nas quartas-feiras, não há visita no presídio, apenas a entrega da “sacola”. 
materiais que a companheira utiliza na confecção dos artesanatos. Nos "dias de criança"2, leva Iara para ver a mãe.

Gregório domina todas as regras da instituição prisional acerca do que é permitido levar na "sacola". Ao longo dos cinco meses em campo, a pesquisadora não viu qualquer item que ele levou ser barrado pela equipe de segurança, diferentemente do que ocorre com a maior parte das pessoas observadas na fila de espera. A perícia dos insumos ocorre dentro da sala de revista, a via de acesso ao interior do cárcere. Lá, a equipe de segurança também inspeciona as roupas e os corpos dos visitantes. Para a revista pessoal, é utilizada a "raquete" ${ }^{3}$. As pessoas da fila afirmam que não há scanner corporal nas prisões, só detector de metal. Para as visitantes, outros procedimentos são reservados. Usando somente lingerie, as mulheres sentam em um banco e tocam o chão três vezes. Os homens não passaram por esse tipo de inspeção. Ainda, aquelas que estão menstruadas precisam fazer a troca do absorvente em frente a uma agente penitenciária. Revista semelhante é feita em bebês, que precisam ter suas fraldas trocadas na presença de algum membro da segurança prisional.

Dentro da prisão, nos dias autorizados, Gregório realiza as visitas íntimas. Ele conta que existe um espaço reservado para esse fim. Trata-se de uma cela desativada com colchão e um banheiro comunitário. "Acontece de $15 \mathrm{em} 15$ dias [...]. Tem privacidade, mas todo mundo sabe pra onde tu tá indo. É um constrangimento, principalmente pra ela". Quando Gregório leva a filha à prisão, não realiza "a íntima". Relata ainda a regra institucional em que "se não usufrui, perda a vaga. Três vezes sem usar, perde a vaga” e não poderá mais ter relações sexuais naquele espaço da prisão. Para prevenir a gestação, Luzia toma o contraceptivo comprado por Gregório.

O entrevistado não comenta com as pessoas que possui uma companheira presa por medo de sofrer preconceito. É frequentemente questionado em seu emprego sobre as razões pelas quais sempre se ausenta algumas horas nas quartas-feiras (dia em que leva a "sacola"). Diz que vai "contornando" esse problema, pois já desenvolveu um repertório de justificativas, caso alguém o confronte. Afirma, ainda, que a maior dificuldade de ter um relacionamento com uma companheira presa é "o tempo". Sempre trabalhou nos finais de semana e seu dia de folga passou a ser o dia da visita.

Quando questionado sobre as motivações para manter o relacionamento com uma companheira presa, ele diz que nunca pensou sobre isso. Depois, relata que desde a juventude é muito vinculado à cultura mangá, na qual "é melhor morrer que se desonrar. A amizade e a lealdade, não abandonar alguém que precisa. $\mathrm{O}$ abandono é uma forma de desamor para mim".

Entende, ainda, que a maior parte dos companheiros não visita as mulheres presas, pois "homens são mais propensos a abandonar em todas as situações. Os homens se sentem mais livres para circular, para a poligamia”.

\section{Teodoro}

Teodoro tem 54 anos, possui ensino superior completo e declara-se branco. É casado com Dinorá, 36 anos, que está presa. Está aposentado em função de um problema crônico de saúde. Sua renda é de $\mathrm{R} \$ 5.300,00$ "quase o teto do INSS". Não recebe outro auxílio do Governo. Possui residência em um município que fica $400 \mathrm{Km}$ da cidade onde sua companheira está detida. A distância e o custo de transporte dificultavam, mas não o impediam, de realizar as visitas. Um dia, na fila de espera da prisão, conheceu Dalva. Ela ofereceu abrigo a ele na capital. Desde então "mora de favor" no segundo andar da casa dela. Como retribuição, ele compra comida e ajuda Dalva a compor a "sacola" da filha presa.

Teodoro foi casado antes, faz 20 anos que se separou de Francisca. Estiveram juntos por 12 anos e tiveram três filhos. Após o divórcio, Teodoro ficou com a guarda da prole e os criou com o auxílio de uma rede de apoio feminina.

Em 2011, após muitos anos solteiro, conheceu Dinorá. Ele foi ao presídio feminino com o intuito de auxiliar na implantação de um projeto religioso para "levar a palavra para a prisão". Lá dentro, apaixonou-se por Dinorá. Ela já tinha cumprido 2 anos e 10 meses de pena quando eles se conheceram. Mantiveram contato por telefone enquanto ela estava no regime fechado. Após a progressão para o semiaberto,

\footnotetext{
${ }^{2}$ Duas vezes ao mês, é permitida a entrada de crianças e adolescentes na prisão.

${ }^{3}$ Aparelho de revista corporal, que emite um som quando é aproximado de algum eletrônico. É um item de segurança comumente utilizado em grandes eventos, como jogos ou shows em estádios.
} 
casaram-se. Dinorá estava utilizando tornozeleira eletrônica e ultrapassou o diâmetro permitido para poder frequentar um curso de esteticista. A punição para essa infração, segundo Teodoro, é "um castigo de 30 dias no (regime) fechado". Dinorá, porém, decidiu não se entregar, ficou foragida por um ano e meio e retornou ao cárcere em outubro de 2016, após denúncia anônima sobre seu paradeiro.

Dinorá é nordestina e aos 13 anos mudou-se para a Região Sul do país para trabalhar como empregada doméstica. Anos depois, seu patrão foi assassinado, esquartejado e enterrado em uma praia. A polícia suspeitava que a esposa da vítima fosse a mandante do crime e, para ter argumento para prender a mulher, implantou droga na casa da suspeita. Como consequência, todos que estavam no domicílio no momento da batida policial foram presos, inclusive Dinorá. Assim, ela foi encarcerada e condenada a 13 anos de prisão por tráfico de entorpecentes. Posteriormente, após a contratação de um advogado pago por Teodoro, a pena foi reduzida para 10 anos.

Teodoro não tinha familiaridade com a prisão antes de conhecer Dinorá. A primeira e única vez que esteve dentro do cárcere foi para auxiliar na implantação do projeto religioso. Nunca esteve encarcerado ou visitou outras pessoas. Diz que já foi discriminado por ter uma companheira detida.

É a única pessoa que visita Dinorá. Leva a sacola duas vezes por semana (quartas-feiras e sábado). Ele narra seu o cotidiano como visitante dentro do cárcere: "Ficamos no pátio, nós só comemos a comida que eu levo [...] E a cada 14 dias tem a íntima. É outra coisa, que se tu não ama muito, tu trai, né? Que homem que fica 14 dias sem transar?". Explica ainda a organização da visita íntima. "Tem uma cama de concreto e um banheiro. A gente leva o lençol e um produto (de limpeza), porque tu nunca sabe o que tem lá!". Diz que são oferecidas duas camisinhas por casal, mas que eles nunca usam. Dinorá não toma anticoncepcional. Teodoro posiciona-se contrário ao uso desse tipo de método contraceptivo "por isso que eu fiz vasectomia, porque pílula é um veneno!”.

Ele fala sobre as suas motivações para manter o relacionamento com uma companheira presa. "Se eu não amasse ela, eu não estaria aqui. Vamos construir uma família... mas se ela fizer outra coisa, não quero mais". Eles planejam ter um filho após a saída de
Dinorá da prisão. Para isso, vai tentar reverter a vasectomia que realizou décadas atrás, após o nascimento de seu terceiro filho que teve com sua primeira esposa.

Teodoro diz que são muitas as dificuldades de ter uma companheira presa, dentre eles o seu problema de saúde e a distância que a prisão fica de sua casa. O maior obstáculo, porém, está em aceitar a injusta prisão dela.

Sobre os motivos pelos quais ele acha que a maior parte dos homens não visita as companheiras presas, Teodoro diz:

porque é melhor pegar mulher na rua. Porque não existe amor. São poucos, pouquíssimos (companheiros que visitam)! Por isso que tem tanta lésbica aí! Se o cara não quer mais, tinha que dizer. Tem gente que só vem para a íntima e às vezes traz uma sacola. Aquelas que descobrem a traição do marido, namorado, desligam! ${ }^{4}$ Tem coisas que são imperdoáveis, mas se é imperdoável, acaba. Não fica indo só na íntima!

\section{Sebastião}

Sebastião, 48 anos, tem ensino médio completo e declara-se branco. Possui união estável com Rosane, de 25 anos. Trabalha há 23 anos em uma empresa metalúrgica e sua renda mensal é $\mathrm{R} \$ 2.200,00$. Mora em um município da região metropolitana com dois filhos e com sua primeira esposa, Nara. Essa, foi atingida por uma bala em abril 2014 e está em estado vegetativo desde então. Sebastião, divide-se entre a rotina de trabalho na metalúrgica, os afazeres domésticos e os cuidados com a primeira esposa. "Em casa, eu passo, cozinho, lavo roupa, pago as contas... não tá fácil, mas as panelas não esvaziaram ainda”. Nem sempre a rotina dele foi assim: "Antes, era ela quem cuidava da casa".

A impossibilidade de uma vida conjugal com a Nara fez com que o entrevistado iniciasse o relacionamento com Rosane. Um ano e meio após o acidente, começaram seu romance. Ao longo da entrevista, Sebastião repetidamente fala sobre o quanto a segunda companheira lembra a primeira. "Quando eu conheci a Nara, ela já tinha uma filha. A Rosane também já tem um filho. Ela teve o filho no hospital, só teve e já tiraram dela". Uma particularidade na tra-

4"Desligar" é retirar a autorização da visita. As mulheres presas podem solicitar essa retirada. 
jetória de Rosane é a fragilidade de sua rede de apoio. Ela foi adotada por quatro famílias. "Ela nunca teve ninguém. Eu tenho que ajudar ela em tudo”.

Após alguns meses de relacionamento, Sebastião e Rosane começaram a morar juntos. "Eu construí uma casa pra ela no terreno dos fundos na minha casa. Não levei ela pra dentro de casa, em respeito à Nara. Todo mundo criticou, foi difícil, mas depois foram aceitando ela". Durante o período que morou no "puxadinho dos fundos", Rosane auxiliava nos cuidados de Nara. Foi nessa casa construída por Sebastião que a nova companheira foi presa em flagrante por porte de drogas e de arma ${ }^{5}$.

Desde abril de 2017, Sebastião tornou-se um visitante na cadeia feminina. Todo sábado acorda às 3h30, para fazer a comida que leva à prisão. Caminha um longo trajeto e pega duas conduções até o presídio da capital. Não cogita não largar essa rotina: "Não vou abandonar ela. Não venho só na íntima. Foi na minha casa, foi errado, mas não vou abandonar. Vou fazer de tudo para tirar ela de lá. Para mim, independente do que ela fez, ela é uma boa pessoa".

Ele também realiza a visita íntima. "Tem que marcar o horário com a (assistente) social. A visita é sábado sim, outro não. Pra mim, é indiferente". Sebastião diz que a companheira não toma anticoncepcional e que eles não usam preservativo. "A prisão não fornece camisinha, nunca me ofereceram, nem nunca vi alguém entrar com uma". A suspeita é que em uma dessas visitas íntimas, Rosane tenha engravidado. Ele ainda desconfia que Rosane tenha planejado engravidar, pois isso a ajudaria no julgamento: "Não sei se alguém disse que grávida pega pena menor. Não sei porque ela ouviu isso! Ela já tá se condenando assim".

Ele elenca os motivos pelos quais mantém o relacionamento com a companheira presa: "Porque eu gosto muito dela. Não vou dizer amor, porque não sei se pode amar uma pessoa e depois outra. O que me mantém com ela, é que eu vejo a Nara nela, nas burradas que ela faz". Ele também se reconhece como responsável pela prisão da companheira. "Eu me sinto culpado, porque eu pressionava ela para ter renda. Eu achava que ela tava vendendo Avon".

O entrevistado entende que a maior dificuldade de ter um relacionamento com uma parceira encarcerada é a ausência. "Não ter aquela pessoa no meu lado. É que nem a Nara, no começo (após o acidente) eu sonhava o tempo todo com ela. Agora isso acontece com a Rosane".

Sebastião diz que sofre preconceito de todo mundo, principalmente dos vizinhos, por ter uma companheira presa. Ele também já viveu estigma por ter sido encarcerado. Cumpriu uma pena de 6 anos por assalto. Durante o período em que "puxou a cadeia”, recebeu visitas de Nara, dos filhos e dos pais. Ele nunca teve outros parentes presos, diz ser "a ovelha negra da família".

Ele comenta sobre os homens que não visitam as companheiras presas. "Não sei se é respeito, mas se tu tá com a pessoa, tu tem que aprender a conviver com a pessoa. Não sei se eles são fracos, ou não querem compromisso. Eu admiro os que estão aqui, respeito".

Diz ainda que conhece vários homens que não vão ao encontro das companheiras presas, mas que recebiam visitas delas enquanto "puxavam a cadeia". Segundo Sebastião, "os homens são fracos. Se ela fez por ti, o que te custa retribuir? [...] E ainda tem gente que só vai na 'íntima'. Não tem que ter a mulher só como objeto, tem que ter como amiga, como companheira". Ele também observa que a instituição prisional feminina contribui para as poucas visitas: "Pra mim, mulher e homem preso tinha que ser igual, mas não é [...] Eu acho elas muito abandonadas, só uma visita por semana, quatro no mês. Elas iam se sentir muito mais valorizadas se tivesse mais dias de visita".

\section{Ciro}

Ciro tem 42 anos, possui ensino médio completo e diz que sua cor é "branco sujo". Mora na capital com a sua mãe e com dois de seus cinco filhos. É proprietário de um prédio e de lá tira sua fonte de renda. "Alugo quatro apartamentos, tenho um mercado e um estacionamento, tudo no mesmo lugar". O faturamento mensal gira em torno de $\mathrm{R} \$ 7.000,00$.

Ciro possui união estável com Brenda, 25 anos, sua atual companheira. O romance começou em setembro de 2016. "Era o primeiro passeio ${ }^{6}$ dela. Ela foi no churrasco de um amigo em comum, aí nos conhecemos". Brenda foi condenada a 5 anos por tráfico de drogas e cumpriu quase metade desse tempo em regime fechado. Já havia iniciado o relacionamento com Ciro, quando foi lhe dada a opção

\footnotetext{
${ }^{5}$ À época da entrevista, Rosane ainda não havia sido julgada.
}

${ }^{6}$ Saída autorizada do regime semiaberto. 
de usar a tornozeleira eletrônica. Forneceu à Justiça o endereço domiciliar dele. Moraram juntos por poucos meses, até ela ser presa novamente. "Tava quase chegando o prazo da [liberdade] condicional e ela esqueceu de carregar a tornozeleira [...] Ela tá de castigo no [regime] fechado. Era pra ser 30 dias, mas já tá 40 aí".

Ciro cita os motivos pelos quais ele mantém o relacionamento com a companheira encarcerada. "Pelo que ela mostrou antes de ser presa. [...] Ela cuidava da casa, dos filhos, da mãe, de mim. Imagina eu com dois filhos e uma mãe de 80 anos. É um corre pra todo lado".

Ciro é a única pessoa que visita Brenda, vai à penitenciária nas quartas-feiras e sábados. Ele narra sua rotina como visitante, sem receio de falar sobre práticas ilegais, como o consumo de drogas ilícitas: "Acordo às 5 horas. Dou uns pega num baseado? Pego o carro. No estacionamento, dou mais uns pega. Aí, vou ali (local da entrada dos visitantes) e fico naquela de coisas que entram e não entram". De fato, a pesquisadora viu vários itens levados por ele serem barrados pela equipe de segurança da penitenciária.

Ciro teve dificuldade para conseguir se cadastrar como visitante, pois a instituição prisional não fornecia a autorização. "Tive que dar baixa em seis processos para conseguir entrar”. Essas não foram as primeiras ações judiciais que ele respondeu. Foi condenado a 9 anos e 8 meses por tráfico de drogas e cumpriu 7 anos no regime fechado. Durante esse período, recebeu visita de várias companheiras e de sua prole que, em parte, foi concebida na prisão: "Quase todos os meus filhos eu fiz na cadeia".

Assim, enquanto estava preso, Ciro tinha facilidade para ter relações sexuais com suas parceiras. Agora, como visitante em um presídio feminino, ele percebe diferenças no que tange os direitos sexuais de homens e mulheres no cárcere. Revela que na prisão masculina, não precisa pedir autorização da instituição para realizar a visita íntima. "Depois que a mulher entrou, deu! As visitas ficam no pátio e a gente faz [sexo] na galeria mesmo". Com as mulheres presas, é diferente:

Os caras fazem uma burocracia para a [visita] íntima [...]. É uma coisa que tinha que ser de direito. A gente tá só na mão, só no arreto $^{8}$, desde que ela foi presa. Coitada das gurias [mulheres presas], elas ficam só se comendo porque é uma burocracia pra fazer a íntima.

Ciro elenca outras dificuldades de ter uma parceira presa: "sinto falta da mulher. Também tem a questão de pagar um advogado. Dou um jeito, ainda mais uma guria que vale a pena, nova, bonita, que me ajuda com os filhos". Diz não ter sofrido preconceito por ter uma companheira presa. "Depois de 10 anos preso, nem teria cabimento. Pode até ter acontecido, mas não que eu tenha notado. Só vou em lugar de gente que goste de mim".

Sobre o pequeno número de homens visitantes, Ciro comenta: "A maioria não visita porque não pode, não porque não querer. Homens não visitam porque estão presos ou tem alguma 'bronca'. Pra eu visitar, tive que dar baixa em seis processos". Fala ainda que alguns homens também não recebem visita na prisão: "Acontece com os homens também, mas para os homens é facilitado, os direitos, ter outra companheira. Sempre ouvi falar que os caras abandonam, mas se o cara trabalha e gosta da mulher, ele visita".

\section{Discussão}

As visitas em prisões de mulheres são entendidas como um fenômeno que envolve laços de afetividade e apoio femininos (Barcinski et al., 2014; Diniz, 2015; Pereira, 2016). Os homens, quando mencionados, costumam ser posicionados pela literatura científica como aqueles que abandonam as suas companheiras presas (Barcinski, 2012; Diuana et al., 2016; Foltran, 2010; Guimarães et al., 2006; Medeiros, 2010; Minayo, \& Ribeiro, 2016; Soares et al., 2014).

Ao longo do trabalho de campo em duas prisões femininas foi observada que essa ausência não é total. Diferentemente do que é encontrado na literatura, os resultados coletados revelam que os companheiros compõem a maior parte do grupo de visitantes masculinos, embora as mulheres, especialmente as mães, ainda sejam maioria em dias de visita nas prisões femininas. Dentre o grupo de homens, além dos laços de conjugalidade, também foi observada no cenário da cadeia feminina a presença de filhos, pais, irmãos e

\footnotetext{
${ }^{7}$ Fuma maconha.

${ }^{8}$ Masturbação.

${ }^{9}$ Processo judicial em andamento.
} 
amigos das mulheres detidas. Tudo isso aponta para a pluralidade de atores nesse espaço.

Os companheiros que visitam suas parceiras se consideram "visitantes de fé", pois todos os finais de semana vão à prisão e todas as quartas-feiras levam a "sacolas". Embora o número de homens encontrado em campo seja tímido, permite problematizar a categoria "abandono" na cadeia de mulheres. Os entrevistados foram convidados a pensar a respeito dessa ausência masculina. Parte deles exime os homens que não visitam as mulheres aprisionadas. Ciro, um dos interlocutores que já esteve preso, entende que os homens não têm condições de ir às prisões femininas, pois estão presos ou respondem a processos judiciais. Essa percepção é convergente com a pesquisa realizada com mulheres presas, em que algumas participantes informavam a impossibilidade de receber visitas de seus companheiros por estarem eles igualmente presos (Simões, 2014).

Os entrevistados também justificam o afastamento de outros cônjuges através de papéis e expectativas sociais atribuídos aos homens, como poligamia e a necessidade de ter relações sexuais frequentes. Tais expectativas indicam um privilégio masculino, visto que as investidas e as práticas sexuais de homens com múltiplas companheiras são toleradas pela sociedade (Beauvoir, 2009), sobretudo se comparadas às mulheres que têm mais de um parceiro sexual.

Do ponto de vista feminino, a infidelidade e o distanciamento do cônjuge representam o esquecimento e a ingratidão, pois muitas mulheres visitavam seus parceiros no cárcere antes de serem presas (Minayo, \& Ribeiro, 2016; Simões, 2014). Os interlocutores que condenam a ausência masculina na cadeia feminina também entendem que os homens ausentes são ingratos, além de desonrados. Ainda, a fraqueza e a fragilidade, antes atributos rejeitados na masculinidade hegemônica, são apontados por entrevistados como elementos que compõe o perfil dos não-visitantes.

Nota-se, também, que o entendimento de abandono é amplo. Para Teodoro e Sebastião, ir apenas nos dias da visita íntima não atesta que o sujeito esteja comprometido com a companheira presa. Ou seja, para quem visita não basta ir à prisão, já que o sentido atribuído ao abandono feminino por parte dos homens que visitam suas parceiras privadas de liberdade envolve uma condenação moral daqueles que frequentam as unidades exclusivamente para as ditas "íntimas".
Sebastião e Ciro, os dois que tiveram experiência de privação de liberdade, emitiram críticas à unidade prisional visitada, sobretudo do que diz respeito à regulação dos direitos sexuais. Eles percebem as diferenças no manejo institucional e no trâmite burocrático para poder realizar as visitas íntimas em prisões femininas e masculinas. Na cadeia de homem, basta a mulher ter acesso ao interior da prisão para que o casal tenha relações sexuais. Não há autorização de assistentes sociais, tampouco perde-se esse direito, caso não usufruam da visita íntima por três vezes seguidas. Ciro, inclusive, afirma que quase toda a sua prole foi concebida durante o período que cumpriu pena, evidenciando as facilidades para a realização de encontros sexuais com mulheres visitantes no cárcere masculino. Ou seja, para os homens que visitam suas parceiras encarceradas e que também são egressos do sistema penitenciário, além de valer a expressão apresentada anteriormente - para quem visita não basta ir à prisão - acrescenta-se outra: as visitas íntimas não só são condenadas moralmente quando não são acompanhadas de outras visitas, como também são consideradas mais reguladas nas unidades prisionais que custodiam mulheres.

Através dos dados coletados em campo, observa-se que os homens visitantes têm outros privilégios, pois só mulheres passam por procedimentos de revista íntima. Assim, ao mesmo tempo que se constata a regulação dos direitos sexuais e reprodutivos das mulheres presas e a invasiva revista nas visitadoras, nota-se que tanto no cárcere masculino quanto no feminino o controle sobre os corpos e sexualidade dos homens é pequena ou inexistente. Segundo Diuana et al. (2016), tais dificuldades são usadas como justificativa, por parte dos companheiros, para o abandono das mulheres na prisão.

Esses obstáculos, somados ao abandono dos parceiros, são apontados por Teodoro e Ciro como as razões pelas quais as mulheres se envolveram afetiva e sexualmente umas com as outras. Tal percepção encontra sustentação em pesquisas realizadas em prisões femininas, nas quais a carência e a impossibilidade de práticas heterossexuais levam internas a ter relações sexuais com outras mulheres detidas (Barcinski, 2012; Simões, 2014).

Os três entrevistados que têm autorização institucional para realizar a visita íntima possuem diferentes experiências quanto ao acesso aos métodos contraceptivos na cadeia de mulheres. Nenhum 
deles refere a oferta institucional de anticoncepcionais. Já a distribuição de preservativos masculinos é controversa. Teodoro afirma que há oferta desse insumo na prisão, enquanto Sebastião diz nunca ter visto camisinhas no local. Para prevenir a gravidez, Gregório compra mensalmente o anticoncepcional oral para sua parceira. Já Teodoro, preocupado com os efeitos nocivos da pílula, que considera "um veneno", realizou vasectomia, anos atrás. Sebastião e sua companheira não tomam qualquer medida preventiva e havia, à época da coleta de dados, a suspeita de que ela tivesse engravidado. Se confirmada a concepção, é um evento raro em cadeia de mulheres. Seja pelo pequeno número de homens visitantes, seja pela imposição institucional de que a população prisional feminina faça uso de contraceptivo injetável, são incomuns histórias de mulheres que engravidaram enquanto presas (Diuana et al., 2016).

Sebastião também confidencia a suspeita de que Rosane, sua parceira, teria engravidado propositalmente, para evitar uma eventual condenação penal. A ideia de Rosane é amparada pelo habeas corpus coletivo concedido pelo Supremo Tribunal Federal para substituir a prisão preventiva por domiciliar a mulheres presas grávidas, ou aquelas que estão detidas e possuem filhos com até 12 anos de idade (Supremo Tribunal Federal, 2018). Contudo, um estudo que observou audiências de custódia de mulheres grávidas que foram presas em flagrante, observou que a maior parte daquelas que respondiam ao crime de tráfico de drogas - como Rosane - não recebeu o benefício da prisão domiciliar e foram sentenciadas à pena de privação de liberdade em cárcere (Moraes, 2018).

Acerca das trajetórias e narrativas do quarteto, nota-se a diversidade nas histórias de vida. Dois deles - Gregório e Teodoro - posicionam-se como visitantes diferentes dos demais, por não terem familiaridade com o cárcere até se tornarem visitadores. A alta escolaridade (ensino superior completo) da dupla de fato destoa da maior parte das pessoas que frequentam o cárcere em dia de visitas. Além disso, esses dois eximem as parceiras de qualquer culpa diante dos crimes pelos quais foram condenadas, diferentemente do que ocorre com Sebastião e Ciro, que tiveram passagens pela prisão.

Por outro lado, algumas semelhanças nos relatos do quarteto chamam a atenção. Todos são homens provedores, financeiramente estáveis e consideravelmente mais velhos que suas parceiras. Além disso, os quatro eram, de algum modo, cuidadores antes do encarceramento de suas parceiras. Gregório e Teodoro foram casados com outras mulheres e ficaram com a guarda da prole após o divórcio. O primeiro, ainda, realizou o registro de paternidade da filha que sua parceira teve com outro homem. Sebastião é o responsável pela esposa debilitada e por todos os afazes domésticos. Ciro cuida da mãe idosa e cria os dois filhos mais velhos. Tais narrativas destoam do que comumente é associado à masculinidade hegemônica (Nascimento et al., 2018), sobretudo no âmbito prisional, na qual o exercício do cuidado é entendido como atestado de fragilidade e feminilidade (Santos, \& Nardi, 2014).

Há de se destacar, contudo, que, com exceção de Gregório, que diz desempenhar as tarefas domésticas desde criança, todos os demais delegavam às suas parceiras ou a outras mulheres os afazeres do lar. Em outras palavras, os elementos que compõem a masculinidade hegemônica não parecem orientar a conduta da maioria dos visitantes, na medida em que os mesmos assumiram o cuidado de pessoas ao longo de suas trajetórias, muito embora não o tenham realizado integralmente. As companheiras de Sebastião e Ciro, inclusive, haviam se tornado as cuidadoras da casa e dos familiares de seus cônjuges, tarefas essas que eram, antes do início da relação amorosa, responsabilidade exclusiva deles. Tais situações rementem ao entendimento do "modelo tradicional" de família, no qual cabe às mulheres o desempenho de das atividades domésticas, enquanto aos homens é conferido o papel de provedores (Hirata, \& Kergoat, 2007).

Tais assimetrias de gênero se somam às trajetórias das mulheres detidas com quem os interlocutores se relacionam. As vidas das quatro são marcadas por vulnerabilidades, perdas e abandonos. Luzia, companheira de Gregório, foi expulsa de casa quando seu então marido soube que ela estava grávida. Dinorá, esposa de Teodoro, saiu da Região Nordeste ainda adolescente para buscar um emprego como doméstica na Região Sul do país. Rosane passou por múltiplos lares e famílias durante sua infância e adolescência. Brenda estava no regime semiaberto quando conheceu Ciro.

Considerando as trajetórias dos entrevistados e de suas parceiras, pode-se pensar, tal qual mencionado pelos interlocutores, que a visita na prisão representa amor, dever e cuidado de homens mais velhos 
e provedores. Ao mesmo tempo, pode-se conjecturar que essas relações representem a possibilidade de exercício de controle e poder masculino sobre essas mulheres presas, visto as fragilidades familiares e sociais que marcam as vidas delas. Nesse sentido, a situação de prisão acirra a situação de vulnerabilidade feminina, colocando-as em posição de dependência perante esses homens, seus únicos visitantes e provedores.

Semelhanças também podem ser observadas quando se estabelece uma comparação dos dados obtidos no presente estudo com a pesquisa de mestrado referida anteriormente, realizada pela primeira autora do presente estudo, com mulheres que têm parceiros encarcerados. Nesse estudo, as mulheres que foram entrevistadas igualmente tinham histórias de vidas marcadas por múltiplas formas de violência e abandono familiar. Nos discursos delas, o sacrifício advindo do não abandono dos parceiros encarcerados é acompanhado pelo desejo de serem recompensadas pelos companheiros. A submissão dessas mulheres, que se percebem obrigadas a manter seus relacionamentos, a prover seus companheiros material e emocionalmente e a suportar as violências impostas pela prisão, é ressignificada a partir do protagonismo expresso por elas. Tal protagonismo se expressa através do poder de decisão das entrevistadas de ir à prisão, de levar seus filhos nas visitas e de fornecer insumos aos seus companheiros. Assim, as privações que o cárcere impõe aos homens presos, de algum modo, fortalecem estas mulheres, pois é potencialmente recompensador investir em homens vulneráveis, sobre os quais elas possam exercer alguma forma de controle.

Deste modo, para os homens entrevistados no presente estudo, a situação de prisão das parceiras parece surgir como um reforço à dependência que elas já tinham de seus cônjuges antes de serem detidas. Já para as mulheres que visitam os companheiros aprisionados, o cárcere promove certa inversão de papéis sociais, em que as mulheres assumem temporariamente o papel de provedoras (materiais e emocionais) dos seus cônjuges presos.

Simultaneamente, nas narrativas dos homens participantes, a visitação no cárcere se configura como um investimento na relação e um ato de abnegação, visto as privações vivenciadas no cotidiano dos entrevistados. A rotina é penosa não apenas para eles, mas para os visitantes de modo geral.
Raríssimas são as pessoas na fila que não carregam "sacolas", o que indica que o transporte de insumos para dentro do cárcere vai além de uma convenção em dia de visitas, trata-se de uma necessidade das mulheres detidas.

Há ainda o estigma de ter uma parceira presa, referido por três dos quatro participantes. Segundo Goffman (1988, p. 39), aqueles que possuem vínculos com algum individuo estigmatizado, vivenciam, "através da estrutura social - uma relação que leva a sociedade mais ampla a considerar ambos uma só pessoa". Nesse sentido, os sujeitos que têm parceiras presas são "obrigados a compartilhar um pouco do descrédito" das mulheres presas com quem eles estabeleceram relações conjugais. Além do estigma, o encarceramento das mulheres teve outras consequências nas vidas dos entrevistados, tais como o crescimento dos gastos mensais em virtude da "sacola" e dos custos com advogados e a necessidade de mudança de cidade e domicílio. Para enfrentar todas as adversidades, os visitantes encontram o apoio nas filas das prisões, em dias de visita. Deste modo, contrastam com o preconceito e a discriminação vivenciados por eles fora da situação de visita.

\section{Considerações finais}

O presente estudo, conduzido em prisões femininas na Região Sul do Brasil, mostra que a ausência dos homens companheiros entre os visitantes não é total. As justificativas atribuídas por eles para o comparecimento nos estabelecimentos penais de mulheres se referem ao amor, ao dever e ao cuidado. No discurso dos participantes, observamos o exercício de masculinidades não hegemônicas, cercadas de práticas de cuidado dirigidas a parentes e, inclusive, às parceiras encarceradas. Ao mesmo tempo, tais condutas de cuidado são permeadas pelo controle e pelo reforço da dependência das companheiras privadas de liberdade.

A finalidade destas análises é problematizar as possibilidades de exercício de masculinidades no cárcere, não de generalizá-las para outros contextos e situações de encarceramento. Neste sentido, outros estudos com homens que visitam parceiras privadas de liberdade podem apontar para outras interpretações do fenômeno do abandono feminino, bem como das visitas e revistas íntimas abordados anteriormente, não sendo pretensão deste estudo indicar um perfil único de visitadores. 
Finalmente, a etnografia com essa parcela do segmento prisional pouco investigada na literatura acadêmica mostra que o entendimento de abandono feminino não é homogêneo, já que alguns dos entrevistados condenam moralmente aqueles que frequentam o cárcere exclusivamente para a visita íntima. Em outras palavras, para os visitantes, não basta visitar.

\section{Referências}

Altenbernd, B., Barcinski, M., \& Lermen, H. S. (2015). Integralidade e intersetorialidade nas práticas psicológicas: Um relato de experiência. Cadernos de Pesquisa, 45(156), 390-408. https://doi.org/10.1590/198053142972.

Barcinski, M. (2012). Expressões da homossexualidade feminina no encarceramento: O significado de se "transformar em homem" na prisão. Psico-USF, 17(3), 437-446. https://doi.org/10.1590/S1413-82712012000300010

Barcinski, M., Lermen, H. S., Campani, C., \& Altenbernd, B. (2014). Guerreiras do cárcere: Uma rede virtual de apoio aos familiares de pessoas privadas de liberdade. Temas em Psicologia, 22(4), 929-940. https://doi.org/10.9788/TP2014.4-19

Bassani, F. (2011). Amor bandido: Cartografia da mulher no universo prisional masculino. Dilemas: Revista de Estudos de Conflito e Controle Social, 4(2), 261-280.

Bassani, F. (2016). Visita íntima: Sexo, crime e negócios nas prisões. Porto Alegre, RS: Bestiário.

Beauvoir, S. (2009). O segundo sexo. Rio de Janeiro, RJ: Nova Fronteira.

Biondi, K. (2009) Junto e misturado: Imanência e transcendência no PCC (dissertação de mestrado). Pós-Graduação em Antropologia Social, Universidade Federal de São Carlos, São Carlos, SP, Brasil.

Borges, J. (2018). O que é encarceramento em massa? Belo Horizonte, MG: Letramento.

Brasil. Ministério da Justiça e Segurança Pública. (2018). Levantamento Nacional de Informações Penitenciárias Infopen Mulheres (2a ed.). Brasília, DF: o autor. Recuperado de http://depen.gov.br/DEPEN/depen/sisdepen/ infopen-mulheres/infopenmulheres_arte_07-03-18.pdf

Carrigan T., Connell, R., \& Lee, J. (1985). Toward a new sociology of masculinity. Theory and Society, 14(5), 551-604.

Carvalho, M. L. Valente, J. G., Assis, S.,G., \& Vasconcelos, A. G. G. (2006). Perfil dos internos no sistema prisional do Rio de Janeiro: especificidades de gênero no processo de exclusão social. Ciência \& Saúde Coletiva, 11(2), 461-471. https://doi.org/10.1590/S1413-81232006000200023

Cunha, M. (2014). The ethnography of prisons and penal ponfinement. Annual Review of Anthropology, 43(1), 217-233. https://doi.org/10.1146/annurev-anthro-102313-030349

Diniz, D. (2015). Cadeia: Relatos sobre mulheres. Rio de Janeiro, RJ: Civilização Brasileira

Diuana, V., Ventura, M., Simas, L., Larouzé, B., \& Correa, M. (2016). Direitos reprodutivos das mulheres no sistema penitenciário: Tensões e desafios na transformação da realidade. Ciência \& Saúde Coletiva, 21(7), 2041-2050. https:// doi.org/10.1590/1413-81232015217.21632015

Einat, T., \& Rabinovitz, S. (2013). A warm touch in a cold cell: Inmates' views on conjugal visits in a maximum-security women's prison in Israel. International Journal of Offender Therapy and Comparative Criminology, 57(12), 1522-1545. https://doi.org/10.1177/0306624X12461475

Foltran, P. J. (2010). A visita nas unidades prisionais e seu papel na mediação do acesso aos direitos da pessoa presa: Uma reflexão acerca das desigualdades de gênero na política penitenciária. Anais do Seminário Internacional Fazendo Gênero, Florianópolis, 2010, 9.

Goffman, E. (1988). Estigma: Notas sobre a manipulação da identidade deteriorada. Rio de Janeiro, RJ: LTC.

Guimarães, C. F., Meneghel, S.,N., Zwetsch, B.,E., Silva, L.,B., Grano, M.,S., Siqueira, T.,P. et al. (2006). Homens apenados e mulheres presas: Estudo sobre mulheres de presos. Psicologia \& Sociedade, 18(3), 48-54. https://doi. org/10.1590/S0102-71822006000300007

Hirata, H., \& Kergoat, D. (2007). Novas configurações da divisão sexual do trabalho. Cadernos de Pesquisa, 37(132), 595-60. https://doi.org/10.1590/S0100-15742007000300005

Lopes, S. S. (2005). Masculinidades encarceradas: Representações sobre o estupro e o estuprador na prisão (dissertação de mestrado). Instituto de Medicina Social, Universidade do Estado do Rio de Janeiro, Rio de Janeiro, RJ, Brasil. 
Medeiros, L. L. (2010). Mulheres e cárcere: Reflexões em torno das redes de proteção social. Anais do Encontro Nacional de História Oral - Testemunhos: História e Política, Recife, PE, Brasil.

Minayo, M. C. S., \& Ribeiro, A. P. (2016). Condições de saúde dos presos do estado do Rio de Janeiro, Brasil. Ciência \& Saúde Coletiva, 21(7), 2031-2040. https://doi.org/10.1590/1413-81232015217.08552016

Modesti, M. C. (2013). Mulheres aprisionadas: As drogas e as dores da privação de liberdade. Chapecó, SC: Argos.

Moraes, L. S. C. (2018). Direito à maternidade e (des)encarceramento feminino no Brasil: Perspectivas éticas e jurídicas da punição criminal (tese de doutorado). Programa de Pós-graduação em Bioética Ética Aplicada e Saúde Coletiva, Universidade Federal do Rio de Janeiro, Rio de Janeiro, RJ, Brasil.

Nascimento, M., \& Connell, R. (2017). Reflecting on twenty years of Masculinities: An interview with Raewyn Connell. Ciência \& Saúde Coletiva, 22 (12), 3975-3980. https://doi.org/10.1590/1413-812320172212.27242016

Nascimento, M. A. F., Uziel, A. P., \& Hernandez, J. G. (2018). Young men in juvenile detention centers in Rio de Janeiro, Brazil: Gender, sexuality, masculinity and health implications. Caderno de Saúde Pública, 34(2), 1-8. https://doi.org/10.1590/0102-311x00177916

Pereira, E. L. (2016). Famílias de mulheres presas, promoção da saúde e acesso às políticas sociais no Distrito Federal, Brasil. Ciência \& Saúde Coletiva, 21(7), 2123-2134. https:// doi.org/10.1590/1413-81232015217.16792015

Pimentel, T. (2018, junho 20). Condenadas': Visitas são raras em penitenciárias femininas, aponta pesquisa da UFMG. G1, Minas Gerais. Recuperado de https://gl.globo.com/mg/minas-gerais/noticia/condenadas-visitas-sao-raras-em-penitenciarias-femininas-aponta-pesquisa-da-ufmg.ghtml

Santos, H. B., \& Nardi, H. C. (2014). Masculinidades entre matar e morrer: O que a saúde tem a ver com isso? Physis, 24(3), p. 931-949 https://doi.org/10.1590/S0103-73312014000300014

Scott, J. (1990). Gênero: Uma categoria útil de análise histórica. Educação e Realidade, 16(2), p. 71-99.

Silva, E. A. (1997). Violência sexual na cadeia: Honra e masculinidade. Revista de Ciências Humanas, 15(21), p. 123-138. https://doi.org/10.5007/\%25x

Simões, G. K. (2014). Etnografia da ala feminina da cadeia pública de Cascavel. Pontourbe, (14), 1-9. https://doi. org/10.4000/pontourbe.1691

Soares, G. P., Félix-Silva, A. V., \& Figueiró, M. E. S. S. (2014). Teatro-menor: Cartografia em arte e experimentação de mulheres em situação de cárcere. Psicologia \& Sociedade, 26(n. spe), 89-99. https://doi.org/10.1590/S0102-71822014000500010

Supremo Tribunal Federal. (2018, fevereiro 20). $2^{\text {a }}$ Turma concede HC coletivo a gestantes e mães de filhos com até doze anos presas preventivamente. Notícias STF. Recuperado de http://www.stf.jus.br/portal/cms/verNoticiaDetalhe.asp?idConteudo=370152

\section{Helena Salgueiro Lermen}

Doutoranda no Programa de Pós-Graduação em Saúde Coletiva do Instituto de Medicina Social da Universidade do Estado do Rio de Janeiro (UERJ). Graduada em Psicologia pela Pontifícia Universidade Católica do Rio Grande do Sul, especialista em Saúde Pública pela Universidade Federal do Rio Grande do Sul, especialista em Saúde Comunitária pela Universidade Federal do Rio Grande do Sul e mestre em Psicologia pela Pontifícia Universidade Católica do Rio Grande do Sul.

E-mail: hslermen@gmail.com

(iD) https://orcid.org/0000-0002-7148-6760

\section{Martinho Braga Batista e Silva}

Professor adjunto do Instituto de Medicina Social da Universidade do Estado do Rio de Janeiro (IMS-UERJ), no Departamento de Políticas e Instituições de Saúde. Graduado em Psicologia na Universidade de Brasília (1999), especialista em Saúde Mental em nível de residência na Fundação Oswaldo Cruz (FIOCRUZ), mestre em Saúde Coletiva no IMS-UERJ e o doutor em Antropologia Social pela Universidade Federal do Rio de Janeiro (UFRJ).

E-mail: silmartinho@gmail.com

(iD) https://orcid.org/0000-0003-3577-958X 
Endereço para envio de correspondência:

Universidade do Estado do Rio de Janeiro, Instituto de Medicina Social. Rua São Francisco Xavier, 524, Pavilhão João Lyra Filho, 6º andar / bloco E, sala 6017. Maracanã - CEP 20550900 - Rio de Janeiro, RJ - Brasil

Recebido 16/08/2018

Aprovado 23/08/2018

Received 08/16/2018

Approved 08/23/2018

Recibido 16/08/2018

Aceptado 23/08/2018

Como citar: Lermen H. S.; \& Silva M. B. B. (2018). Masculinidades no Cárcere: Homens que Visitam suas Parceiras Privadas de Liberdade. Psicologia:Ciênciae Profissão,38(n.spe.2),73-87.https://doi.org/10.1590/1982-3703000212034

How to cite: Lermen H. S.; \& Silva M. B. B. (2018). Masculinities Inside Prison: Men who Visit their Female Partners Deprived of Liberty. Psicologia:Ciência e Profissão, 38(n.spe.2), 73-87. https://doi.org/10.1590/1982-3703000212034

Cómo citar: Lermen H. S.; \& Silva M. B. B. (2018). Masculinidades en la Cárcel: Hombres que Visitan a sus Compañeras Privadas de Libertad. Psicologia: Ciência e Profissão, 38(n.spe.2), 73-87. https://doi.org/10.1590/1982-3703000212034 